\title{
Erratum to "Effect of Long-Term Climbing Training on Cerebellar Ataxia: A Case Series"
}

\author{
Marianne Anke Stephan, ${ }^{1}$ Sylvie Krattinger, ${ }^{2}$ Jérôme Pasquier, ${ }^{3}$ Shahid Bashir, ${ }^{1}$ \\ Thomas Fournier, ${ }^{3}$ Dieter Georg Ruegg, ${ }^{1}$ and Karin Diserens ${ }^{4}$ \\ ${ }^{1}$ Department of Medicine, University of Fribourg, 1700 Fribourg, Switzerland \\ ${ }^{2}$ Neurological Center Plein Soleil, 1010 Lausanne, Switzerland \\ ${ }^{3}$ Department of Mathematics, University of Fribourg, 1700 Fribourg, Switzerland \\ ${ }^{4}$ Unit of Early Neurorehabilitation, Department of Clinical Neurosciences, University Hospital, 1011 Lausanne, Switzerland \\ Correspondence should be addressed to Marianne Anke Stephan; marianne.stephan@alumni.ethz.ch
}

Received 12 December 2013; Accepted 17 December 2013; Published 3 February 2014

Copyright (C) 2014 Marianne Anke Stephan et al. This is an open access article distributed under the Creative Commons Attribution License, which permits unrestricted use, distribution, and reproduction in any medium, provided the original work is properly cited.

The authors' names were incorrectly listed as Stephan Marianne Anke, Krattinger Sylvie, Pasquier Jérôme, Bashir Shahid, Fournier Thomas, Ruegg Dieter Georg, and Diserens Karin; this error is corrected here. 


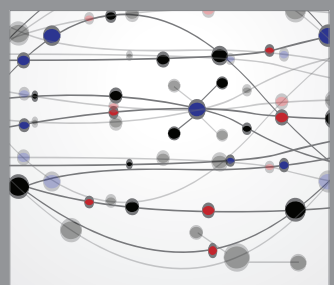

The Scientific World Journal
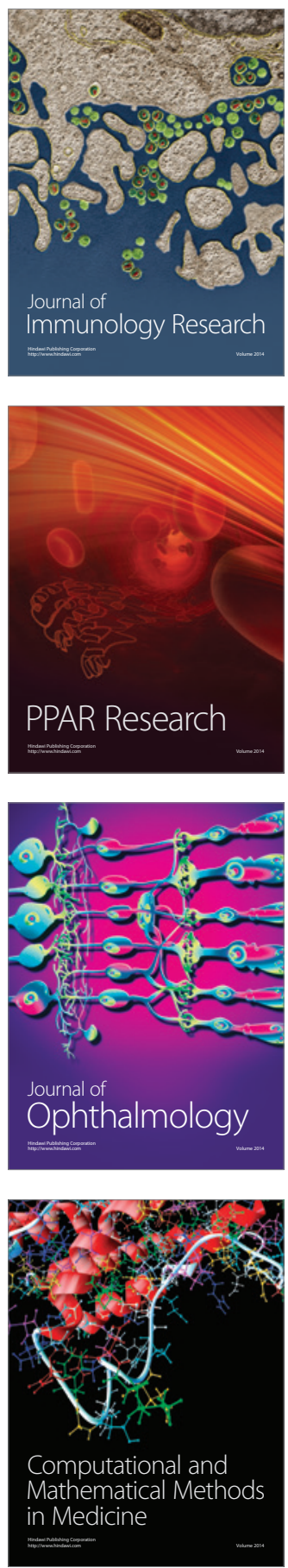

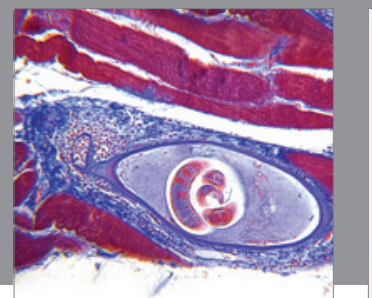

Gastroenterology

Research and Practice
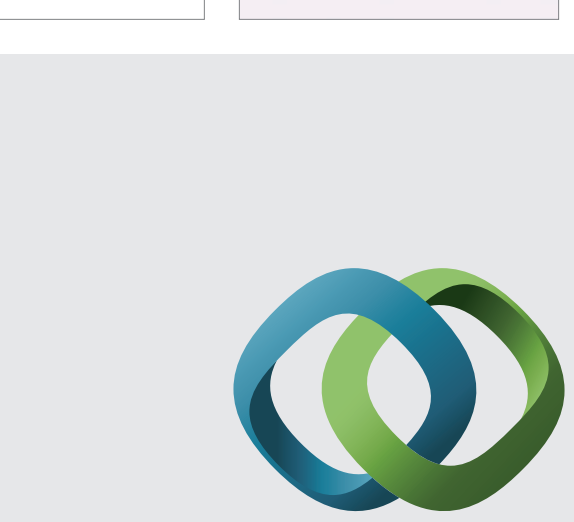

\section{Hindawi}

Submit your manuscripts at

http://www.hindawi.com
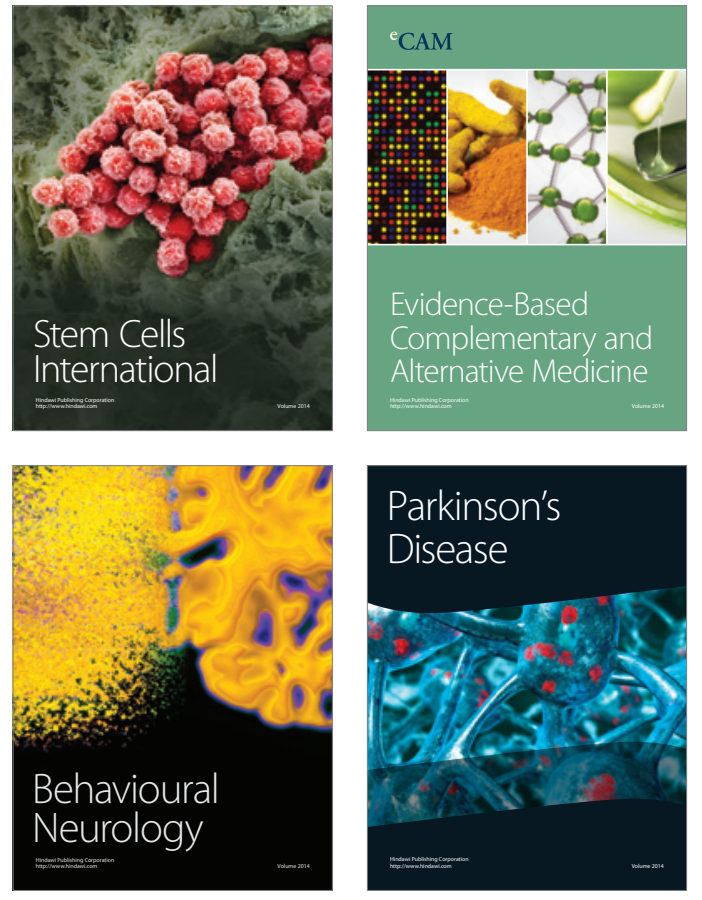
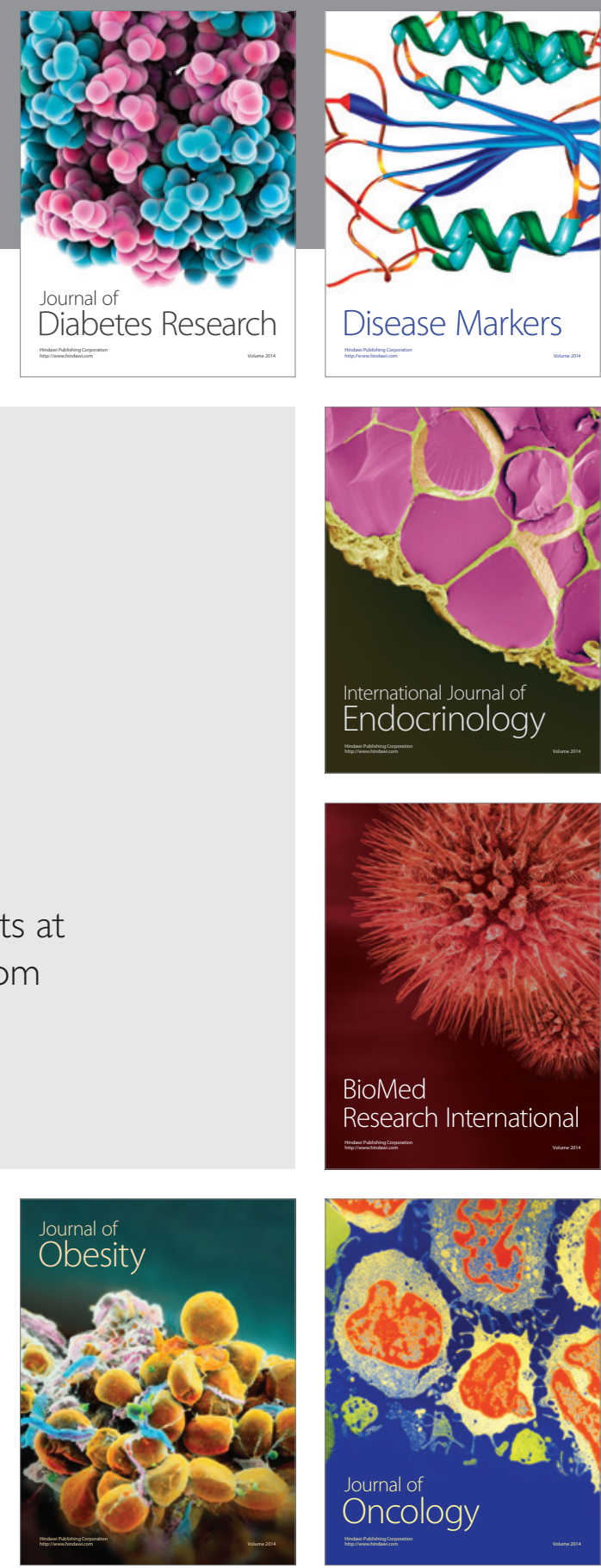

Disease Markers
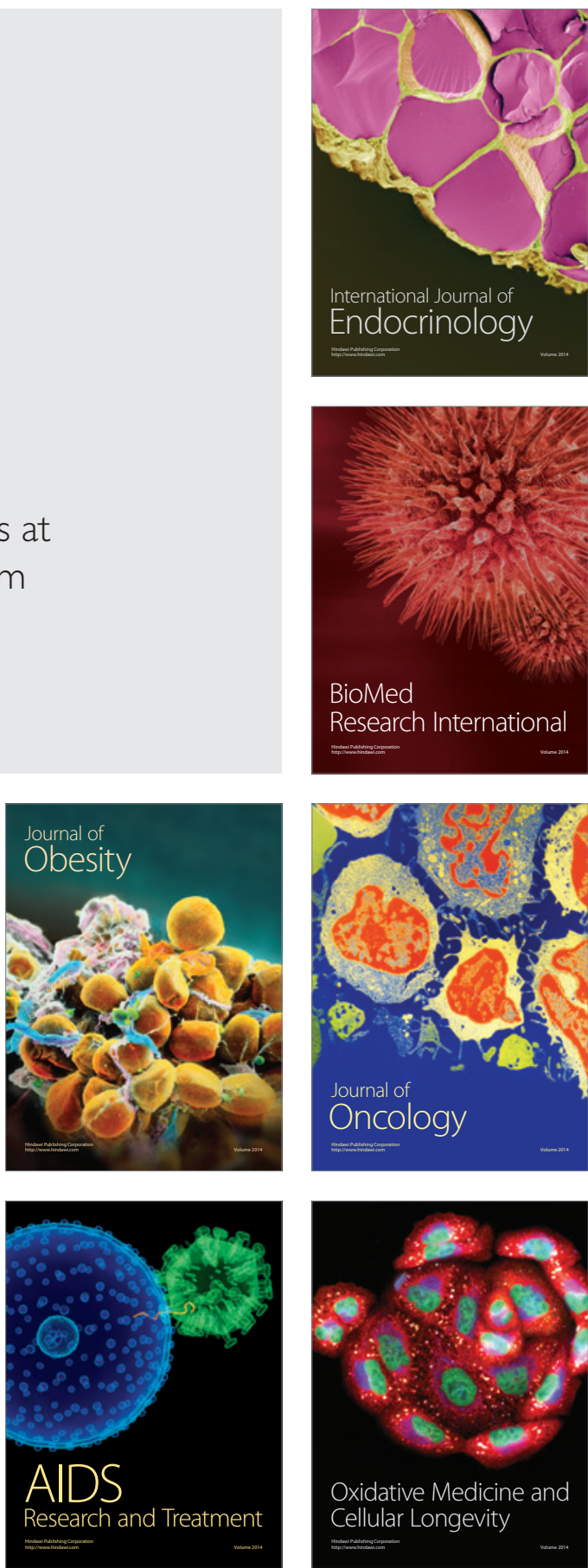